increase the capacity to support more patients within existing resources and deliver a wider range of therapeutic interventions.

To achieve accessibility for the maximum number of patients, services were established in eight different locations including providing therapy within GP practices and community halls, and also inreaching to meet the needs of dementia patients in a nursing home setting.

Whilst the philosophy was unchanged, the service was redesigned and continues to develop responsively and with flexibility. A diverse range of therapeutic interventions are available and a plan of care is tailored to meet the individual patient and carer needs following assessment. New volunteer roles with specific profiles were developed to augment the nursing staff. The community engagement officer increases awareness to diverse and often hard to reach groups.

Evidence from patient reported outcome measures, piloting and evaluation enable creative and on going service design to meet emerging needs. Structured training programmes for staff and volunteers continue.

Increased access to the service is evidenced by data collection, demonstrating a $51 \%$ increase countywide, with $70 \%$ increase of 18-64 age group and 74\% increase in non cancer patients, demonstrating greater opportunities for those with life limiting illnesses to be supported to reach their full potential.

This service will be sustained and enhanced by working in partnership, signposting, and through additional innovation such as commissioned Carers Assessment.

- Lincolnshire Research Observatory.

http://www.research-lincs.org.uk/Latest-Population.aspx

\section{P24 TESSERA AND BEYOND}

1,2Jannette Smith, 'Julia O'Neill. 'Hospice Care for Burnley and Pendle, Burnley, Lancashire, ${ }^{2}$ East Lancashire Hospitals NHS Trust

\subsection{6/bmjspcare-2013-000591.46}

For the past 10 years, Pendleside have made one of their Day Therapy days available to non palliative patients. The day referred to as Early Diagnosis Day (EDD) was essentially aimed at patients with a recent cancer diagnosis being treated with curative intent.

Whilst the EDD was innovative and popular initially, more lately it had become stagnated and predicable. It was also recognised that it was not fully in line with the work being done locally and nationally which has "survivorship" as a key element.

Patients were consulted and responded enthusiastically to the ideas suggested for service improvement. Indeed the TESSERA name was chosen by a patient group.

It is acknowledged that a cancer diagnosis can be shattering and life changing. With appropriate support patients can and do rebuild their lives. It was on this basis that the name was chosen. A Tessera is an individual tile used in creating a mosaic. Which was thought to be an ideal representation of rebuilding in the finest form.

TESSERA:

Together,

Experience,

Solace,

Survivorship,

Empowerment,

Rehabilitation,

Adapt.
TESSERA offers an eight week rolling programme of activities, presentations and interactive workshops delivered by outside agencies in addition to Hospice and Trust staff. This is further complemented by peer and healthcare support including an extended MDT.

The day runs from $10 \mathrm{am}-3 \mathrm{pm}$.

Sessions are offered using a menu 'pick and mix' system. Attendance can be one session or a full day (and anything in between). Graduated arrival enables higher patient flow.

Exercise classes, Tai Chi, Emotional Wellbeing and Fatigue Management groups are timetabled as fixed sessions. These all contribute to the ultimate aim of empowering patients to regain a lifestyle that is enriched both emotionally and physically.

\section{P25 TRANSFORMING DAY CARE SERVICES ACROSS BOUNDARIES}

Gaberielle Linehan, Caroline Snow. St Raphael's Hospice

\subsection{6/bmjspcare-2013-000591.47}

South of England Hospice, population of 370,000-380.000, 14 inpatient beds and community team supporting approximately 300 patients.

Day care services previously delivered via a care model unchanged in twenty years; all day attendance with no defined focus.

A service review in 2011 demonstrated that on average 33 patients attended over four days from a community case load of approximately 300 (cost $£ 4545.45$ per patient). Referrals from the CNS team took on average two to three weeks to be processed to arrange a 'look around'. Following this $40 \%$ of patients were unable to attend due to condition deterioration. A CNS caseload review demonstrated the patient demographic was changing to younger more discerning patients wanting specific treatments for attendance.

Day care services were suspended in May 2012 for a refurbishment project. This allowed a rethink on the parameters of the service, aiming to focus, energise and engage.

Service reopened in October 2012 delivering morning or afternoon sessions each with a specific focus. Lead for day care changed to a therapist with nurse support. Activities include, Hope course, art and craft, yoga, music therapy, bathing service on one afternoon, complimentary therapies, lunch clubs and an information centre once a month for all patients /relatives.

Focus of engagement changed from CNS referral to direct patient contact with a choice in activities. Attendance: STEP 1three months accessing two sessions weekly plus a lunch club: then STEP 2- choice of one activity monthly and a lunch club. Eliminates need for discharge and allows for ongoing monitoring and engagement with hospice.

In the six months to March 2013 there has been engagement with 89 patients', representing an increase of $166.8 \%$ over the 6 month period reducing the cost per patient to $£ 1685.39$.

User feedback is positive and active ongoing service review and development is planned.

\section{Community engagement and volunteering}

\section{\begin{tabular}{|l|l}
\hline P26 ESV IS JUST THE START \\
\hline
\end{tabular}}

Karen Filsell, Gillian Levy. Children's Hospice Association Scotland, Edinburgh, UK

10.1136/bmjspcare-2013-000591.48 